\title{
Examining Health Beliefs, Attitudes and Behaviours Relate to Complementary and Orthodox Medicine Use in Chinese Population
} Yinghi Huang ${ }^{1}$ and Adrian Furnham ${ }^{1,2 *}$

${ }^{1}$ Research Department of Clinical, Educational and Health Psychology, University College London, London ${ }^{2}$ Norwegian Business School (BI), Nydalveien, Olso, Norway

\begin{abstract}
The objective of this study was to examine Chinese attitudes to Complementary and Orthodox Medicine. Three groups of participants $(\mathrm{N}=199)$ : complementary medicine $(\mathrm{CM})$ users, orthodox medicine $(\mathrm{OM})$ users, and "neutral" users completed a questionnaire on attitudes towards and behaviours concerning the use of CM and OM. The results indicated that the three groups did not differ in health locus of control, health awareness, perceived importance of psychological factors, and satisfaction with General Practitionerss. All users preferred using OM for H1N1 flu (swine flu) despite a higher perceived disease knowledge in CM group. OM users had more positive attitudes to science than CM users. Participants had higher general efficacy expectation for the type of medicine they used more frequently and the three groups had different perceived OM and CM efficacy for different types of illnesses; CM was considered by all groups to be better for disease prevention and chronic illnesses whereas OM was thought to be more effective in curing acute diseases. Limitations are considered.
\end{abstract}

Keywords: Beliefs; Attitudes; Chinese

\section{Introduction}

Differences between Complementary medicine $\mathrm{CM}$ and $\mathrm{OM}$ (Orthodox Medicine) have been analysed by Aakster (1989) [1] who notes that they differ in their models of thinking, epidemiology, clinical features, diagnostic procedures, treatment, prevention, doctor-patient relationship and position of patient. Though individuals may have stronger belief in one of the two approaches, in general, they use both types of medicine [2]. Eisenberg et al. [3] indicated that people use CM for chronic diseases more often than for serious illnesses. Vincent and Furnham (1996) [4] found that the ineffectiveness of OM for particular problems was one of the main reasons why people turned to CM. Various studies have looked a the choice of medical practitioner (OM vs $\mathrm{CM}$ ) in the west $[5,6]$. This study will examine the issue in China.

A number of factors associated with the choice of OM and CM have been examined.

\section{Locus of control}

A number of studies [5-8] reported the perceived provider control in $\mathrm{CM}$ patients was lower than that in $\mathrm{OM}$ patients. Others found that CM clients had stronger perceived self-control $[8,9]$. However, higher internal control was not a significant predictor of CM use in the study by Astin (1998) [10] though a trend was seen in the data. Similarly, Sirois and Gick (2002) [11] failed to find a stronger belief in self-control over health in CM patients. OM patients were sometimes said to perceive more threat to health [5], but again, the finding was not consistent.

\section{Health awareness}

Western CM clients tend to have higher health self-awareness $[6,9,11]$. Furnham et al. [12] reported that acupuncture patients had most concern for the effect of mental and psychological state on physical health, compared to OM patients and other type of CM patients. Vincent and Furnham [13] found that acupuncture patients' belief of importance of the psychological factors in health maintenance was positively associated with the belief of efficacy of CM. Furnham and Kirkcaldy [6] reported that CM patients were more likely than OM patients to attribute psychological factors to be causes of diseases.

\section{Perceived risk}

Uncertainty is an inevitable experience by patients, especially for those with chronic illnesses [14]. A positive correlation between knowledge of cancer genetics and use of CM has been confirmed by study [15] on cancer survivors, and a positive association between perceived risk and CM use was found in unaffected people, but not in cancer patients. It has been consistently demonstrated that risk and knowledge perception are important factors motivating people to seek information or professional help for health related issues [16,17], supporting the Health Belief Model [18] which suggests that perceived susceptibility is a strong contributor in preventive health behaviours. H1N1 flu (swine flu) was a relatively unfamiliar infectious disease at the time the current research was conducted, thus it was intriguing to investigate people's attitudes and therapeutic choice for illnesses that they never experienced and were unfamiliar with.

\section{Perceived efficacy}

Some OM practitioners argued that many forms of complementary therapies had not been rigorously tested as conventional OM had been, and that the perceived efficacy of CM had not been proven and lacked a scientific base [19]. In response, complementary practitioners claimed that some of their approaches were in fact untestable using the OM testing standard [20]. Vincent, Furnham and Willsmore (1995) [21] investigated the perceived efficacy of acupuncture, homeopathy, herbalism, osteopathy and OM in curing major, minor, chronic and psychological problems. CM was thought to be most efficacious for healing minor and chronic diseases by both OM and CM patients, but $\mathrm{OM}$ was seen to be more efficacious for major conditions.

${ }^{*}$ Corresponding author: Adrian Furnham, Educational and Health Psychology, University College London, 26 Bedford Way, London, WC1H0AP, UK, Tel:00 44 207679 5395; E-mail: a.furnham@ucl.ac.uk

Received July 08, 2013; Accepted August 07, 2013; Published August 09, 2013

Citation: Huang Y, Furnham A (2013) Examining Health Beliefs, Attitudes and Behaviours Relate to Complementary and Orthodox Medicine Use in Chinese Population. Altern Integ Med 2: 135. doi:10.4172/2327-5162.1000135

Copyright: ( 2013 Huang Y, et al. This is an open-access article distributed under the terms of the Creative Commons Attribution License, which permits unrestricted use, distribution, and reproduction in any medium, provided the original author and source are credited. 


\section{Patient expectations}

The effects of patients' expectation in clinical settings have been investigated by numerous studies [22-27]. All of them showed that decision making in clinical settings was strongly affected by patients' expectations of effective medication. For instance, patients' expectation to receive medication influenced actual prescription [22] and greater expected benefit tended to bring better treatment outcomes [28]. It is likely that high expectation for CM efficacy draws patients to the therapy. Moreover, expectations are often formed by inferring from past experience [29], thus, people's medical history is likely to influence their expectation, then treatment choices and possibly, the treatment outcome.

\section{Perceptions of physicians}

What patients' experience during consultations with their General Practitioners (GPs) and with CM practitioners can be fundamentally different due to the nature of the treatment and the communication styles the practitioners adopt? GPs are generally perceived to be more "formal" than complementary practitioners are [30], but CM practitioners tend to give more time for consultation [31] and may enjoy the advantage of the "power of touch"-compared to GPs, CM practitioners seem to undertake physical examination more frequently. Furnham and Kirkcaldy (1996) [6] reported that GP practice was less satisfied by CM patients. The results from the two studies contradicted with the earlier finding by Furnham and Forey (1994) [5] which found little difference in satisfaction with GPs between OM and CM patients; however, a significant difference between the two groups in the perception of competence of CM practitioners was observed.

\section{Research in China}

Most of the research interested in people's health beliefs, attitudes, and behaviours related to CM use was conducted in Western countries, where the use of $\mathrm{OM}$ is generally considered to be the conventional approach. However, in Oriental countries, where many indigenous therapies are being viewed as traditional and conventional, people's decision process to choose between therapies may differ from their western counterparts [32]. The high prevalence of the use of Traditional Chinese Medicine (TCM)-more than 90\% Chinese people have used TCM in lifetime [33], and the fact that TCM composes part of the Chinese health care system [34] may give rise to a unique pattern of use of CM in the Chinese population. For example, a survey [3] in United States reported that respondents who made more visits to $\mathrm{CM}$ practitioners were those with higher education and income. In contrast, a population-based survey [35] in Hawaii reported that CM users had higher rate of reporting financial difficulties.

Chua and Furnham (2008) [36] compared Singaporeans and UK residents' attitudes to medicine use and found that Singaporeans had more positive attitudes to $\mathrm{OM}$ than to $\mathrm{CM}$, although it was predicted that the special role of TCM in Singapore due to its immigration history might make TCM more preferable. UK participants appeared to be more open to CM experience compared to Singaporeans and health consciousness level was higher in UK participants than in Singaporean participants. However, the results may only be applicable for studying medical attitudes in Singaporean's multicultural society (which is composed by Chinese, Malay, Indian and Eurasian Singaporeans), but less informative for other Oriental culture.

The hypotheses derived from the studies above were:

1. The frequency of $\mathrm{CM}$ and $\mathrm{OM}$ use will not correlate with demographic factors as both types of medicine have similar accessibility and high prevalence in the Chinese population.

2. CM users may have (a) greater health awareness, and (b) attach more importance to the role of self control and healthy state of mind in recovering from illnesses, since most of the complementary therapies require patients to take an active role in the healing process.

3. People consult CM practitioner because they believe the treatment will be effective for their problems, and the value of the therapy chimes with their personal health beliefs [4]. OM will be the preferable choice regardless of the group classification differences. CM users might attach less importance to the modern science base for medical treatments since many forms of CM have not undergone or failed being proven by modern scientific tests

4. OM users should have higher expectation for $\mathrm{OM}$ in treating illnesses successfully, whereas CM users should expect CM to be more effective in most circumstances they encounter.

5. OM may be perceived to have highest efficacy in curing major diseases, and CM in curing minor and chronic illnesses. The perceived efficacy for each type of treatment may differ between groups and vary according to disease conditions.

6. CM patients may express less satisfaction with their general practitioners [37].

7. Most CM users will show stronger belief that $\mathrm{CM}$ is more powerful in disease prevention than OM users.

\section{Method \\ Participants}

A total of 199 participants took part in the study. Participants were students (16.1\%), staff (22.6\%) randomly selected from 3 universities in China, and employees (40.7\%) from 2 local companies. The rest were pedestrians $(20.6 \%)$ who were interviewed on streets. There were $99(49.7 \%)$ males and $100(50.3 \%)$ females. The average age was 29.9 years ( $\mathrm{SD}=8.3$ years), with the oldest participant to be 55 years old and youngest 19 years old. The majority (81.4\%) has obtained an undergraduate degree $(\mathrm{N}=121)$ or a diploma $(\mathrm{N}=41)$. Most were single $(55.8 \%)$.

Among the 199 participants whose responses were used for the study, 52 (26.1\%) were OM users (OM group), 95 (47.7\%) were CM users (CM group) and 52 (26.1\%) used both types of medicine equally frequently (neutral group). Subjects were divided into the 3 groups according to their ratings to questions asking the frequency of their attendance to $\mathrm{OM}$ and $\mathrm{CM}$ therapies. If the frequency of using $\mathrm{OM}$ exceeded the frequency of using other types of medicine, then the subject belonged to OM group. If the frequency of using either the traditional Chinese medicine (TCM) or other types of CM was greater than the frequency of using OM, participants would be considered as CM users. Respondents who used OM and alternative types of medicine (comparison was between $\mathrm{OM}$ and the most frequently used complementary medicine-either TCM or other CM) equally frequently composed the neutral user group.

\section{Measure}

Health locus of control: 2 inventories were employed: 21 questions by Lau and Ware (1981) [38] were subdivided into 4 scales, namely the chance health outcomes scale, provider control over health scale, self control over health scale and general health threat scale. 18 questions by 
Wallston et al. (1978) [39] composed 3 subscales labelled belief in selfcontrol, powerful others control and chance health outcomes.

Positive attitude to science: 4 questions by Furnham et al. (1995) [12] testing the perceived relationship between effective medical treatments and scientific methodology.

Medical history: 10 questions asking about health status, medical experience, and frequency of using Traditional Chinese Medicine (TCM), other Complementary medicine and western orthodox medicine.

Health awareness [5]: 11 questions on behaviours of looking for health related information and diet habits.

General expectation for treatment efficacy: 2 questions on the level of expectation for $\mathrm{CM}$ and $\mathrm{OM}$ efficacy.

Satisfaction with general practitioners [5]: 6 questions on orthodox treatment experience and satisfaction with the contact with GPs.

Perceived treatment efficacy by type of illness [12]: a list of 12 illnesses which can be categorised as major (cancer, pneumonia, heart disease), minor (common cold, hay fever, menstrual problems), chronic (arthritis, asthma, back pain) and psychological problems (depression, stop-smoking, stress) were used to test the perceived efficacy of CM (acupuncture, herbalism, homeopathy, osteopathy) and OM.

Perceived risk and self-perceived level of knowledge under uncertainty: 6 questions were used to assess subjects' perceived risk of getting infected with $\mathrm{H} 1 \mathrm{~N} 1 \mathrm{flu}$, perceived disease knowledge level, knowledge source, and related behaviours of seeking help from $\mathrm{OM}$ or CM practitioners.

Perceived $\mathrm{OM}$ and $\mathrm{CM}$ efficacy in disease prevention and cure: 3 questions.

The role of mental health and psychological factors [12]: 4 questions on the perceived importance of psychological factors on health.

\section{Procedure}

Ethical permission was sought and granted. The questionnaire was first translated into Chinese by the first author, then an independent interpreter translated the Chinese version back into English to allow comparison with the original version, and the Chinese version was modified. Questionnaires were distributed in three Chinese universities, two local companies, and to pedestrians by the first author. All subjects who volunteered to participate were asked to finish the questionnaires honestly without time constraint and were assured anonymity. The questionnaire took about 20 minutes to complete. There was about a $50 \%$ response rate as a function of the length of the questionnaire.

\section{Results}

\section{Demographic correlates and medical history}

Hypothesis 1 was generally supported. Correlation analysis showed that sex, age, education, marital status, occupation, and income level did not correlate with the use of CM. (See Table 1). However, age was negatively correlated with the use of OM. Respondents' health status and medical history was analysed with Chi-square test. But results failed to show a difference between OM and CM users. The three groups did not differ in their number of chronic illnesses $\left(\mathrm{X}^{2}(2, N=199)=1.68, p>.05\right)$,

\begin{tabular}{|c|c|c|}
\hline Psychological factors & $\begin{array}{l}\text { Frequency } \\
\text { of OM use (r) }\end{array}$ & $\begin{array}{l}\text { Frequency } \\
\text { of CM use (r) }\end{array}$ \\
\hline Sex & -.049 & -.036 \\
\hline Age & $-.198^{* *}$ & .004 \\
\hline Education & -.008 & .074 \\
\hline Income & -.045 & .054 \\
\hline Chance health outcomes [38] & $-.147^{*}$ & .011 \\
\hline Provider control over health [38] & .042 & -.012 \\
\hline Self control over health [38] & .039 & -.070 \\
\hline General health threat [38] & .117 & -.077 \\
\hline Belief in self control over health [39] & -.015 & .070 \\
\hline Powerful others control over health [39] & -.004 & -.069 \\
\hline Chance health outcome [39] & -.094 & -.059 \\
\hline Positive attitude to science & $.175^{\star}$ & -.127 \\
\hline Health Awareness & -.023 & .102 \\
\hline OM expectation & $.357^{* *}$ & -.060 \\
\hline CM expectation & -.009 & $.346^{\star *}$ \\
\hline Satisfaction with GP & $.167^{*}$ & -.021 \\
\hline Risk of infecting $\mathrm{H} 1 \mathrm{~N} 1 \mathrm{flu}$ & .045 & $.188^{* *}$ \\
\hline Perceived Knowledge about H1N1 flu & $.230^{* *}$ & -.117 \\
\hline seek help from GP for H1N1 flu & $.248^{\star *}$ & .086 \\
\hline OM more useful for H1N1 flu & .139 & -.015 \\
\hline CM more useful in preventing diseases & .082 & $.134^{*}$ \\
\hline OM has quicker effect & .073 & $.142^{*}$ \\
\hline $\begin{array}{l}\text { OM more helpful for acute diseases \& CM more } \\
\text { for chronic diseases }\end{array}$ & .128 & .098 \\
\hline Perceived importance of psychological factors & .136 & .032 \\
\hline
\end{tabular}

$* * r<.01$

${ }^{*} r<.05$

Table 1: Pearson Correlations between various factors and frequency of OM and CM use.

number of serious illnesses in the last five years $\left(\mathrm{X}^{2}(2, N=199)=3.00\right.$, $p>.05)$, and number of psychological problems $\left(X^{2}(2, N=199)=1.58\right.$, $p>.05)$.

Health locus of control, health awareness, the importance of psychological factor, and satisfaction with general practitioner

Inconsistent with hypothesis 2 and hypothesis 7, MANOVA indicated that in general, there was no significant difference between the 3 groups in health locus of control, neither when the Lau and Ware (1981)'s [38] scale nor the Wallston et al. (1978)'s [39] scale was used. Sub-scale analysis also failed to demonstrate any between group differences in chance health outcomes, provider control, self control over health, and general health threat. Moreover, one-way ANOVA did not reveal any significant group difference in health awareness and in the perceived importance of psychological factors. In addition, psychological factors were considered to be highly important for physical health by 3 users groups who responded similarly, and the item-by-item rating can be seen in Table 2. Likewise, the 3 groups of users had similar level of satisfaction with their general practitioners.

\section{Perceived risk and self-perceived level of knowledge of h1n 1} flu

One-way ANOVA test was used to examine the difference between the user groups in their perceived risk of being infected with H1N1 flu, self-perceived level of knowledge and health related behaviours during the outbreak of the disease. Statements and ratings by each group were presented in Table 3. 


\begin{tabular}{|c|c|c|c|c|}
\hline & \multicolumn{3}{|c|}{ Mean rating } & \multirow{4}{*}{$\boldsymbol{F}$} \\
\hline & \multicolumn{3}{|c|}{ (SD) } & \\
\hline & $\begin{array}{l}\text { OM } \\
\text { group }\end{array}$ & $\begin{array}{l}\text { CM } \\
\text { group }\end{array}$ & $\begin{array}{l}\text { Neutral } \\
\text { group }\end{array}$ & \\
\hline & $(\mathrm{N}=52)$ & $(\mathrm{N}=95)$ & $(\mathrm{N}=52)$ & \\
\hline \multirow{2}{*}{$\begin{array}{l}\text { 1. Being fit and well depends as much on your } \\
\text { state of mind as on the functioning of your } \\
\text { body. }\end{array}$} & 6.00 & 5.79 & 5.58 & \multirow[t]{2}{*}{1.04} \\
\hline & (1.19) & $(1.59)$ & $(1.6)$ & \\
\hline \multirow{2}{*}{$\begin{array}{l}\text { 2. Psychological treatments (e.g., relaxation, } \\
\text { counselling) should be used much more widely. }\end{array}$} & 6.15 & 5.65 & 5.36 & \multirow[t]{2}{*}{$3.89^{*}$} \\
\hline & $(0.96)$ & $(1.6)$ & $(1.61)$ & \\
\hline \multirow{2}{*}{$\begin{array}{l}\text { 3. The "will to live" can be a significant factor in } \\
\text { whether people recover from a serious illness } \\
\text { or injury. }\end{array}$} & 5.64 & 5.67 & 5.31 & \multirow[t]{2}{*}{1.19} \\
\hline & (1.27) & $(1.49)$ & $(1.45)$ & \\
\hline \multirow{2}{*}{$\begin{array}{l}\text { 4. State of mind is a crucial part of achieving } \\
\text { better health-by promoting positive feelings a } \\
\text { person can enhance their physical health. }\end{array}$} & 5.94 & 5.67 & 5.69 & \multirow[t]{2}{*}{0.63} \\
\hline & (1.09) & $(1.6)$ & $(1.53)$ & \\
\hline \multirow[t]{2}{*}{ perceived importance of psychological factors } & 5.93 & 5.69 & 5.49 & \multirow[t]{2}{*}{1.64} \\
\hline & $(0.91)$ & $(1.34)$ & $(1.4)$ & \\
\hline
\end{tabular}

$1=$ strongly disagree $7=$ strongly agree

${ }^{*} \mathrm{p}<0.05$

Table 2: Mean of perceived importance of psychological factors on health

\begin{tabular}{|c|c|c|c|c|}
\hline & \multicolumn{3}{|c|}{ Mean rating } & \\
\hline & \multicolumn{3}{|c|}{ (SD) } & \multirow{3}{*}{$F$} \\
\hline & $\begin{array}{l}\text { OM } \\
\text { group }\end{array}$ & $\begin{array}{l}\text { CM } \\
\text { group }\end{array}$ & \begin{tabular}{|l|} 
Neutral \\
group
\end{tabular} & \\
\hline & $(\mathrm{N}=52)$ & $(\mathrm{N}=95)$ & $(\mathrm{N}=52)$ & \\
\hline \multirow{2}{*}{$\begin{array}{l}\text { 1. I feel I am at high risk after the WHO has } \\
\text { increased the influenza pandemic alert level } \\
\text { for swine flu }\end{array}$} & 3.61 & 3.77 & 4.36 & \multirow[t]{2}{*}{2.81} \\
\hline & $(1.74)$ & $(1.76)$ & $(1.71)$ & \\
\hline \multirow{2}{*}{$\begin{array}{l}\text { 2. I pay more attention to personal hygiene } \\
\text { since the outbreak of the swine flu. }\end{array}$} & 5.06 & 4.9 & 5.38 & \multirow[t]{2}{*}{1.94} \\
\hline & $(1.24)$ & $(1.4)$ & $(1.42)$ & \\
\hline \multirow[t]{2}{*}{ 3. I feel I do not know much about the swine flu } & 4.88 & 3.98 & 4.25 & \multirow[t]{2}{*}{$6.68^{*}$} \\
\hline & $(1.29)$ & $(1.34)$ & $(1.67)$ & \\
\hline \multirow{2}{*}{$\begin{array}{l}\text { 4. There are a lot of resources that can help } \\
\text { me to learn more about swine flu if I want to }\end{array}$} & 5.36 & 5.42 & 5.52 & \multirow[t]{2}{*}{0.14} \\
\hline & $(1.49)$ & $(1.43)$ & $(1.45)$ & \\
\hline \multirow{2}{*}{$\begin{array}{l}\text { 5. I will seek help from my general practitioner } \\
\text { (instead of from practitioners of complementary } \\
\text { therapy) immediately if I think I may have } \\
\text { gotten infected with swine flu. }\end{array}$} & 5.98 & 5.55 & 5.56 & \multirow[t]{2}{*}{1.51} \\
\hline & $(1.29)$ & $(1.59)$ & $(1.6)$ & \\
\hline \multirow{2}{*}{$\begin{array}{l}\text { 6. Orthodox medicine is more useful in curing } \\
\text { swine flu patients. }\end{array}$} & 5.38 & 4.9 & 4.67 & \multirow[t]{2}{*}{2.6} \\
\hline & $(1.43)$ & (1.6) & (1.89) & \\
\hline
\end{tabular}

${ }^{*} \mathrm{p}<0.01$

Table 3: Ratings of risk, knowledge perception and health related behaviours during outbreak of $\mathrm{H} 1 \mathrm{~N} 1$ flu.

\section{Positive attitude to science}

As predicted there was a significant difference between the groups in attitude to science. Pairwise comparison with the Ryan Procedure (REGWQ) indicated that the CM users had significantly less positive attitude to statements (as shown in Table 4) which emphasize a modern scientific base for medical treatments compared to the OM group. The neutral group responded more compromisingly and did not significantly differ from the other 2 groups.

\section{General expectation for treatment efficacy}

Significant difference was seen in the expectation for the efficacy of orthodox treatment in the 3 groups, as well as in the expected efficacy of complementary treatment, where OM users showed higher expectation for orthodox treatments and CM users showed higher expectation for complementary treatments to successfully cure health problems. These are in line with hypothesis 5 . The mean ratings of expectation for each type of therapy are shown in Table 5. Higher rating means higher expectation.

\section{Perceived efficacy of $\mathrm{OM}$ and $\mathrm{CM}$ in treating different types of illnesses}

Supporting hypothesis 6, MANOVA demonstrated that the 3 user groups significantly differed in their perceived efficacy of acupuncture, homeopathy, and osteopathy in treating major illnesses. But they all tended to believe that $\mathrm{OM}$ was the most efficacious approach for major conditions, followed by herbalism. Only the OM users considered that $\mathrm{OM}$ and herbalism had significantly different effect for major illnesses $(t(43)=3.33, p<0.01)$. For CM and Neutral users, the perceived efficacy difference between these 2 types of treatments in treating major problems was slight and did not reach a significant level.

Also, for minor conditions, the perceived efficacy of OM differed in the 3 groups. Specifically, post hoc comparison with the Ryan Procedure (REGWQ) showed that the differences were between OM and Neutral groups, and between $\mathrm{CM}$ and Neutral groups. OM and herbalism were considered by all user groups to have highest efficacy in treating minor problems.

In addition, for chronic conditions, the 3 groups differed in their views to the efficacy of homeopathy and osteopathy. However, post hoc pairwise comparison failed to detect these differences. For all users, acupuncture and herbalism were the most effective treatment for chronic diseases. For OM users, orthodox treatment was not significantly less effective, but it was rated by CM users to be the least effective way (significantly less effective than acupuncture and herbalism) to treat chronic illnesses.

For psychological problems, between-group difference in perceived efficacy of treatments did not reach significance, especially when post hoc pairwise comparisons were made. $\mathrm{OM}$ and herbalism were

\begin{tabular}{|c|c|c|c|c|}
\hline & \multicolumn{3}{|c|}{ Mean rating } & \multirow{4}{*}{$F$} \\
\hline & \multicolumn{3}{|l|}{ (SD) } & \\
\hline & $\begin{array}{l}\text { OM } \\
\text { group }\end{array}$ & $\begin{array}{l}\text { CM } \\
\text { group }\end{array}$ & $\begin{array}{l}\text { Neutral } \\
\text { group }\end{array}$ & \\
\hline & $(\mathrm{N}=52)$ & $(\mathrm{N}=95)$ & $(\mathrm{N}=52)$ & \\
\hline \multirow{2}{*}{$\begin{array}{l}\text { 1. Medicine is a science and should be } \\
\text { based on rigorous scientific principles }\end{array}$} & 5.96 & 5.48 & 5.57 & \multirow[t]{2}{*}{1.96} \\
\hline & $(1.27)$ & $(1.51)$ & (1.51) & \\
\hline \multirow{2}{*}{$\begin{array}{l}\text { 2. Treatments which are not based } \\
\text { on modern scientific discoveries are } \\
\text { worthless. }\end{array}$} & 4.46 & 3.78 & 4.43 & \multirow[t]{2}{*}{$3.34^{*}$} \\
\hline & (1.94) & $(1.81)$ & $(1.68)$ & \\
\hline \multirow{2}{*}{$\begin{array}{l}\text { 3. Every treatment should be thoroughly } \\
\text { tested by doctors and scientists before } \\
\text { people are allowed to try it. }\end{array}$} & 5.71 & 4.83 & 5.31 & \multirow[t]{2}{*}{$4.37^{*}$} \\
\hline & (1.51) & $(1.97)$ & $(1.64)$ & \\
\hline \multirow{2}{*}{$\begin{array}{l}\text { 4. Complementary therapies should be } \\
\text { scientifically evaluated }\end{array}$} & 5.79 & 5.53 & 5.14 & \multirow[t]{2}{*}{2.08} \\
\hline & $(1.42)$ & $(1.68)$ & $(1.74)$ & \\
\hline \multirow[t]{2}{*}{ Positive Attitudes to Science } & 5.48 & 4.9 & 5.11 & \multirow[t]{2}{*}{$4.55^{\star}$} \\
\hline & $(1.16)$ & $(1.03)$ & $(1.17)$ & \\
\hline
\end{tabular}

$1=$ strongly disagree $7=$ strongly agree

${ }^{*} \mathrm{p}<0.05$

Table 4: Positive Attitudes to Science.

\begin{tabular}{|c|c|c|c|c|}
\hline & \multicolumn{3}{|c|}{ Mean rating } & \multirow[b]{3}{*}{$F$} \\
\hline & \multicolumn{3}{|l|}{ (SD) } & \\
\hline & OM group & CM group & Neutral group & \\
\hline & $(\mathrm{N}=52)$ & $(\mathrm{N}=95)$ & $(\mathrm{N}=52)$ & \\
\hline \multirow[t]{2}{*}{ Expectation for OM } & 5.12 & 3.99 & 4.98 & \multirow[t]{2}{*}{$11.71^{\star *}$} \\
\hline & (1.5) & $(1.52)$ & $(1.64)$ & \\
\hline \multirow[t]{2}{*}{ Expectation for CM } & 3.35 & 4.46 & 4.25 & \multirow[t]{2}{*}{$7.29^{*}$} \\
\hline & $(1.67)$ & $(1.73)$ & $(1.76)$ & \\
\hline
\end{tabular}

${ }^{*} p<0.01{ }^{* *} p<0.001$

Table 5: Expectation for the efficacy of OM and CM. 
perceived to be more effective than other treatments in resolving psychological problems. For both OM and CM users, acupuncture was seen as the least effective approach in treating psychological problems. Table 6 demonstrated the mean scores of perceived efficacy for each type of therapies under different conditions.

\section{Perceived $\mathrm{OM}$ and $\mathrm{CM}$ efficacy in disease prevention and cure}

The three user groups all agreed that CM was better than OM in disease prevention, but OM had quicker effect and was better for acute illnesses. No significant difference was seen between the 3 groups, which did not correspond with hypothesis 8 .

\section{Discussion}

Significant differences between the 3 groups were only found in

\begin{tabular}{|c|c|c|c|c|c|}
\hline \multirow[t]{2}{*}{$\begin{array}{l}\text { Disease } \\
\text { category }\end{array}$} & \multirow[t]{2}{*}{ Therapy } & OM group & CM group & $\begin{array}{l}\text { Neutral } \\
\text { group }\end{array}$ & \multirow[t]{2}{*}{$F$} \\
\hline & & $(\mathrm{N}=52)$ & $(\mathrm{N}=95)$ & $(\mathrm{N}=52)$ & \\
\hline \multirow[t]{10}{*}{ Major } & \multirow[t]{2}{*}{ Acupuncture } & 1.86 & 2.26 & 2.47 & \multirow[t]{2}{*}{$5.22^{* *}$} \\
\hline & & $(0.93)$ & $(0.84)$ & (1.1) & \\
\hline & \multirow[t]{2}{*}{ Herbalism } & 2.73 & 3.05 & 2.74 & \multirow[t]{2}{*}{1.03} \\
\hline & & (1.01) & $(0.89)$ & $(0.98)$ & \\
\hline & \multirow[t]{2}{*}{ Homeopathy } & 1.98 & 2.48 & 2.52 & \multirow[t]{2}{*}{$4.53^{*}$} \\
\hline & & $(0.83)$ & $(0.86)$ & (1.1) & \\
\hline & \multirow[t]{2}{*}{ Osteopathy } & 1.85 & 2.32 & 2.15 & \multirow[t]{2}{*}{$3.76^{*}$} \\
\hline & & $(0.93)$ & $(0.91)$ & $(1.01)$ & \\
\hline & \multirow{2}{*}{$\begin{array}{l}\text { Orthodox } \\
\text { medicine }\end{array}$} & 3.24 & 3.26 & 3.03 & \multirow[t]{2}{*}{2.37} \\
\hline & & $(0.92)$ & $(0.90)$ & $(1.13)$ & \\
\hline \multirow[t]{10}{*}{ Minor } & \multirow[t]{2}{*}{ Acupuncture } & 2.2 & 2.46 & 2.5 & \multirow[t]{2}{*}{1.64} \\
\hline & & $(1.04)$ & $(0.89)$ & $(1.07)$ & \\
\hline & \multirow[t]{2}{*}{ Herbalism } & 3.34 & 3.34 & 3.16 & \multirow[t]{2}{*}{0.71} \\
\hline & & $(0.97)$ & (1.03) & $(0.89)$ & \\
\hline & \multirow[t]{2}{*}{ Homeopathy } & 2.08 & 2.5 & 2.44 & \multirow[t]{2}{*}{$3.10^{*}$} \\
\hline & & $(0.85)$ & $(0.77)$ & $(0.95)$ & \\
\hline & \multirow[t]{2}{*}{ Osteopathy } & 1.97 & 2.36 & 2.19 & \multirow[t]{2}{*}{$4.63^{*}$} \\
\hline & & $(0.77)$ & $(0.83)$ & (0.91) & \\
\hline & \multirow{2}{*}{$\begin{array}{l}\text { Orthodox } \\
\text { medicine }\end{array}$} & 3.74 & 3.52 & 3.03 & \multirow[t]{2}{*}{$6.99^{* *}$} \\
\hline & & $(0.78)$ & $(0.91)$ & (1) & \\
\hline Chronic & Acupuncture & 3.51 & 3.56 & 3.58 & 0.03 \\
\hline & & $(1.08)$ & $(0.88)$ & $(0.97)$ & \\
\hline & Herbalism & 3.06 & 3.43 & 3.26 & 1.51 \\
\hline & & $(1.1)$ & $(0.95)$ & $(0.80)$ & \\
\hline & Homeopathy & 2.68 & 3.09 & 2.77 & $3.25^{*}$ \\
\hline & & $(0.910)$ & $(0.71)$ & $(1.02)$ & \\
\hline & Osteopathy & 3.01 & 3.34 & 2.92 & $4.15^{\star}$ \\
\hline & & $(0.79)$ & $(0.82)$ & $(0.97)$ & \\
\hline & Orthodox & 3.04 & 2.95 & 2.97 & 0.03 \\
\hline & medicine & $(1.03)$ & $(1.07)$ & $(1.05)$ & \\
\hline Psychological & Acupuncture & 1.93 & 2.29 & 2.4 & $3.25^{*}$ \\
\hline & & $(1.02)$ & $(0.90)$ & $(1.08)$ & \\
\hline & Herbalism & 2.48 & 2.7 & 2.53 & 0.59 \\
\hline & & $(1.06)$ & $(0.92)$ & (1.01) & \\
\hline & Homeopathy & 2.06 & 2.39 & 2.52 & 2.55 \\
\hline & & $(0.82)$ & $(0.98)$ & (1.11) & \\
\hline & Osteopathy & 2.27 & 2.5 & 2.44 & 0.82 \\
\hline & & $(0.87)$ & $(0.78)$ & $(0.98)$ & \\
\hline & Orthodox & 2.81 & 2.8 & 2.64 & 0.54 \\
\hline & medicine & $(0.94)$ & $(0.93)$ & (1.06) & \\
\hline
\end{tabular}

Mean (SD) $1=$ not at all effective; $5=$ =very effective ${ }^{*} p<0.05{ }^{* *} p<0.01$

Table 6: Perceived efficacy of therapies by type of condition. positive attitudes to science, general expectation for treatment efficacy, perceived efficacy of different treatments for different disease types, and self-perceived knowledge of H1N1 flu.

The result that there was a negative correlation between age and the frequency of using OM but no correlation between age and CM use means that in our participant sample, people in a younger age used OM more frequently, but there was little relation between age and CM use. Cultural differences were clearly shown, as well as a difference in the medical systems. Patients in western countries, especially in UK or US, consult their registered GP for free, but need to pay for CM services. In contrast, Chinese people are subsidized both when they consult a western medicine doctor or a traditional Chinese medicine practitioner. The finding suggests that why people attend a particular therapy may not solely depends on internal factors like personal beliefs but also is constrained by external factors such as costs and accessibility of the type of treatments.

The second hypothesis that CM users are more likely to have an internal health locus of control, higher health awareness, and higher level of perceived importance of psychological factors was not supported. Although CM addresses the importance of patients' active role in maintaining their own health, and emphasizes the relation between illnesses and the "wholeness" (general bodily function instead of specific symptoms), CM users do not have a more internal health locus of control compared to other groups of medicine users. Sirois and Gick (2002)'s [11] finding was replicated. Also, comparable to OM users, CM users did not perceive any greater or less threat, which was in line with results by Furnham and Bhagrath [9].

The results may be explained thus. Firstly, the ethnic difference between the current study and the previous research contributed at least partly to the conflicted findings. Chua and Furnham [36] reported Singaporeans to be less health aware than UK participants. A public health survey in UK by Lip et al. [40] indicated that among the diverse ethnic groups in UK, Asians were less influenced by public health campaign, showed less health consciousness about dietary content and were less likely to take regular exercises compared to whites and Afro-Caribbean. It is possible that the Chinese respondents' health awareness may be less influenced by external sources such as publicity and medical professions therefore health awareness is not a factor that can distinguish Chinese CM and OM users. Secondly, it has been indicated that frequent/established CM users are more health aware than less frequent/newly established CM users [11]. After taking this factor into account in a follow-up, we found that within CM group, there was a positive correlation between the frequency of CM use and health awareness $(\mathrm{r}=0.243, \mathrm{p}<0.05)$.

Psychological support was once seen as a complementary part to conventional patient care, but now it has been integrated into the process of orthodox treatment, especially for patients suffering from major illnesses such as cancer [41]. Such change might reflect an increasing awareness of the importance of mental health in the population, and this development may have profoundly influenced OM users within the recent decade. Although in earlier research OM users were found to attach less importance to psychological factors compared to CM users [12], the difference between the two groups may become smaller nowadays. Nevertheless, it is not clear whether this change is only limited to the Chinese population.

Results demonstrated that CM users had higher level of selfperceived knowledge of H1N1 flu compared to OM users. But the perceived risk level was similar for the three groups, which was in 
line with results yielded from the general threat measurement from the locus of control scale. Interestingly, all users responded that they would consult $\mathrm{OM}$ if they were infected with H1N1 flu. Hypothesis 3 was partly supported. It may be the case that under uncertain situation, people prefer to use a conventional way (consult an OM practitioner) to solve the problem. Equally it is possible that certain types of treatment approaches are perceived to be more effective for certain types of illnesses. As Furnham and Forey [5] discussed, for illnesses with serious consequences and poor prognosis, people tended to seek help from $\mathrm{OM}$ practitioners.

The current study only focuses on the self-perceived knowledge of the user groups and it seems that the knowledge perception does not influence people's treatment choices for unfamiliar diseases like H1N1 flu.

The hypothesis that CM users have fewer positive attitudes to the idea that medical treatments should have a rigorous science base was supported by the results. The finding by Furnham et al. [12] has been replicated. However, CM users' less positive attitude to science should not be misinterpreted as "a flight from science" [21]. For patients, pragmatism may be more essential for making treatment decisions [37]. Medicine users may be more concerned about the efficacy of a treatment even though they are aware that some of the treatments may lack scientific evidence in current available testing paradigms. As Jobst [42] pointed out, "lack of evidence is not evidence of lack of effect". The raise of integrated medicine which refers to a selective incorporation between CM and OM [43] is a sign for the improvement.

Interestingly, the results indicated that not only CM patients had strong beliefs that $\mathrm{CM}$ was better than $\mathrm{OM}$ in disease prevention and treating chronic problems, OM patients did not disagree. Although the results revealed that different users may not differ largely in perceiving the role of $\mathrm{OM}$ and $\mathrm{CM}$ in preventing and curing illnesses, they held significantly different expectation for the efficacy of the treatments, with $\mathrm{OM}$ users had more faith in OM treatment and believed that $\mathrm{OM}$ was more helpful for their own health issues, CM users in the contrast, expected CM to be more able to solve their problems. Such discrepancy in expectation for OM and CM treatment may be due to users' different medical history. However, the results showed that the three groups did not differ in their chronic, severe and psychological illnesses history. Nevertheless, other factors which were not covered by the questionnaires like family members' health problems and related health behaviours might contribute to the formation of expectation. This conjecture needs to be confirmed by further research. Kalauokalani et al. [28] argued that expectation not only affects people's therapeutic decisions, but also the treatment effects. They showed that people tended to benefit more from the type of treatment in which they held higher efficacy expectation. If this happens, high expectation may become a factor for medicine users to continue a treatment, say, $\mathrm{CM}$ users continue to use CM therapies and develop faith with efficacy.

As predicted, OM was considered by all users to be the most effective treatment for major conditions. However, in the Chinese population, CM and neutral users also seem to perceive herbalism to be as efficacious as OM in treating major diseases. While most research [21] demonstrated that CM was perceived to have greatest efficacy in curing chronic and minor problems, the $\mathrm{CM}$ and $\mathrm{OM}$ respondents also believe that $\mathrm{OM}$ can be very effective in curing minor conditions but not a best choice for chronic health problems compared to the acupuncture and herbalism. Vincent and Furnham's research [13] showed that acupuncture was perceived by acupuncture clients to be most effective in curing psychological problems, but the current study showed that it was perceived by all groups of users to be the least effective approach. Instead, OM and herbalism had the highest perceived efficacy for psychological problems.

The formation of perceived efficacy of a treatment partly depends on individuals' medical experiences and health history. Since herbalism and western orthodox medicine are two very important, if not the most, forms of medical approaches that have comparable high prevalence in the Chinese population, the direct experience and accessibility may render the two treatments to be most likely to be considered to have high efficacy in many conditions by a large number of users. The findings that $\mathrm{OM}$ was thought to be efficacious for minor conditions and acupuncture to have least efficacy in psychological problems contrast what has been found in the early western studies [21]. Those studies also showed that CM patients had more concern about the harmful effect of OM, so it may be argued that such concern might push CM patients to complementary therapies in minor disease conditions, and cause $\mathrm{CM}$ users to give higher efficacy rating to $\mathrm{CM}$ in these conditions.

Given that the CM and OM users in the current study did not differ in health awareness measure, the harmful effect of OM was probably not a major concern for the Chinese CM users. Hence OM was thought to be efficacious in minor diseases. Although the cultural differences may have contributed to the conflicting results when compared with earlier research, it is also possible that the perception of medicine efficacy changes over time. With a blending between the incorporable elements between $\mathrm{CM}$ and $\mathrm{OM}$, such as the rising profile of integrated medicine, the perceived $\mathrm{CM}$ and $\mathrm{OM}$ efficacy in many conditions may have become more similar.

The hypothesis that CM users have lower satisfaction with GPs was not supported by the results. Therefore, dissatisfaction with GPs may not compose a reason for Chinese CM users to make their therapeutic decisions to choose $\mathrm{CM}$ more frequently. This result was not in line with the finding from Furnham and Kirkcaldy (1996)'s [6] study which reported CM patients were less satisfied with their GPs, but paralleled Furnham and Forey (1994)'s [5] result that there was little difference in satisfaction with GPs between OM and CM patients. Like Furnham and Forey (1994)'s [5] suggestion, CM patients might be attracted to $\mathrm{CM}$ practice because of the perceived competence of the practitioners rather than a dissatisfaction with OM service. Notably, in Furnham and Kirkcaldy (1996)'s [6] research, young people were found to be more inclined to use OM, thus the different satisfaction level with GPs between CM and OM groups might reflect an age influence. Due to a limited age range in the current study, the age influence was unclear. Perhaps another reason for the similar satisfaction level is that in China, procedures and clinical settings of the $\mathrm{OM}$ and $\mathrm{CM}$ (herbalism in particular) practices are to some extent more similar than are in Western countries. For example, both types of treatments are available in almost all hospitals, and both types of practitioners are called "doctor".

Clearly there are cultural similarities and differences between the attitudes to, beliefs about and reasons for consulting $\mathrm{CM}$ and $\mathrm{OM}$ practitioners. Many of these results merit replication and extension in a bigger, more representative Chinese sample whose medical history is known. This study used a non representative and opportunistic sample which merits replication to ensure the validity of the results. It is also worth doing further research on lay perceptions of the efficacy of these treatments for different diseases.

\section{References}

1. Aakster CW (1989) Assumptions governing approaches to diagnosis and treatment. Soc Sci Med 29: 293-300. 
Citation: Huang Y, Furnham A (2013) Examining Health Beliefs, Attitudes and Behaviours Relate to Complementary and Orthodox Medicine Use in Chinese Population. Altern Integ Med 2: 135. doi:10.4172/2327-5162.1000135

Page 7 of 7

2. Helman C (1990) Culture, Health and Illness (2nd edn) Oxford: ButterworthHeineman.

3. Eisenberg DM, Kessler RC, Foster C, Norlock FE, Calkins DR, et al. (1993) Unconventional medicine in the United States. Prevalence, costs, and patterns of use. N Engl J Med 328: 246-252.

4. Vincent C, Furnham $A(1996)$ Why do patients turn to complementary medicine? An empirical study. Br J Clin Psychol 35 : 37-48.

5. Furnham A, Forey J (1994) The attitudes, behaviors and beliefs of patients of conventional vs. complementary (alternative) medicine. J Clin Psychol 50 458-469.

6. Furnham A, Kirkcaldy B (1996) The health beliefs and behaviours of orthodox and complementary medicine clients. Br J Clin Psychol 35 : 49-61.

7. Furnham A, Smith C (1988) Choosing alternative medicine: a comparison of the beliefs of patients visiting a general practitioner and a homoeopath. Soc Sci Med 26: 685-689.

8. Kelner M, Wellman B (1997) Who seeks alternative health care? A profile of the users of five modes of treatment. J Altern Complement Med 3: 127-140.

9. Furnham A, Bhagrath R (1993) A comparison of health beliefs and behaviours of clients of orthodox and complementary medicine. Br J Clin Psychol 32 237-246.

10. Astin JA (1998) Why patients use alternative medicine: results of a nationa study. JAMA 279: 1548-1553.

11. Sirois FM, Gick ML (2002) An investigation of the health beliefs and motivations of complementary medicine clients. Soc Sci Med 55: 1025-1037.

12. Furnham A, Vincent C, Wood R (1995) The health beliefs and behaviors of three groups of complementary medicine and a general practice group of patients. J Altern Complement Med 1: 347-359.

13. Vincent C, Furnham A(1997) Complementary medicine: a research perspective Chichester: Wiley \& Sons.

14. Neville KL (2003) Uncertainty in illness. An integrative review. Orthop Nurs 22 206-214.

15. DiGianni LM, Kim HT, Emmons K, Gelman R, Kalkbrenner KJ, et al. (2003) Complementary medicine use among women enrolled in a genetic testing program. Cancer Epidemiol Biomarkers Prev 12: 321-326.

16. Brain K, Gray J, Norman P, Parsons E, Clarke A, et al. (2000) Why do women attend familial breast cancer clinics? J Med Genet 37: 197-202.

17. Bluman LG, Borstelmann NA, Rimer BK, Iglehart JD, Winer EP (2001) Knowledge, satisfaction, and perceived cancer risk among women diagnosed with ductal carcinoma in situ. J Womens Health Gend Based Med 10: 589-598.

18. Becker MH, Drachman RH, Kirscht JP (1974) A new approach to explaining sick-role behavior in low-income populations. Am J Public Health 64: 205-216.

19. Fontanarosa PB, Lundberg GD (1998) Alternative medicine meets science. JAMA 280: 1618-1619

20. Hunter A, Grant A (2005) Complementary medicine and evidence-based practice: power and control in healthcare questions about and arranged marriage. Evidence-Based Integrative Medicine 2: 189-194.

21. Vincent C, Furnham A, Willsmore M (1995) The perceived efficacy of complementary and orthodox medicine in complementary and general practice patients. Health Educ Res 10: 395-405.

22. Cockburn J, Pit S (1997) Prescribing behaviour in clinical practice: patients' expectations and doctors' perceptions of patients' expectations--a questionnaire study. BMJ 315: 520-523.

23. Britten N (1995) Patients' demands for prescriptions in primary care. BMJ 310 1084-1085.

24. Webb S, Lloyd M (1994) Prescribing and referral in general practice: a study of patients' expectations and doctors' actions. Br J Gen Pract 44: 165-169.

25. Britten N (1994) Patient demand for prescriptions: a view from the other side. Fam Pract 11: 62-66
26. Bradley CP (1992) Uncomfortable prescribing decisions: a critical incident study. BMJ 304: 294-296

27. Virji A, Britten N (1991) A study of the relationship between patients' attitudes and doctors' prescribing. Fam Pract 8: 314-319.

28. Kalauokalani D, Cherkin DC, Sherman KJ, Koepsell TD, Deyo RA (2001) Lessons from a trial of acupuncture and massage for low back pain: patient expectations and treatment effects. Spine (Phila Pa 1976) 26: 1418-1424.

29. DeCanio SJ (1979) Rational expectations and learning from experience. Quarterly Journal of Economics 93: 47-57.

30. King K, Shaw J, Bochner F, Brooks PM (1985) Therapeutics. Alternative medicine. Medical Journal of Australia 142: 547-551.

31. Hewer W (1983) The relationship between the alternative practitioner and his patient. A review. Psychother Psychosom 40: 172-180.

32. Xue CC, Zhang AL, Greenwood KM, Lin V, Story DF (2010) Traditional chinese medicine: an update on clinical evidence. J Altern Complement Med 16: 301 312 .

33. $\mathrm{Xu} \mathrm{H}$, Chen $\mathrm{K}$ (2008) Integrative medicine: the experience from China. J Altern Complement Med 14: 3-7.

34. Chung V, Wong E, Woo J, Lo SV, Griffiths S (2007) Use of traditional chinese medicine in the Hong Kong special administrative region of China. J Altern Complement Med 13: 361-367.

35. Maskarinec G, Shumay DM, Kakai H, Gotay CC (2000) Ethnic differences in complementary and alternative medicine use among cancer patients. J Altern Complement Med 6: 531-538.

36. Chua SA, Furnham A (2008) Attitudes and beliefs towards complementary and alternative medicine (CAM): a cross-cultural approach comparing Singapore and the United Kingdom. Complement Ther Med 16: 247-253.

37. Bakx K (1991) The 'eclipse' of folk medicine in western society. Sociology of Health and IIIness 13: 17-24.

38. Lau RR, Ware JF Jr (1981) Refinements in the Measurement of health-specific locus-of-control beliefs. Med Care 19: 1147-1158.

39. Wallston KA, Wallston BS, DeVellis R (1978) Development of the Multidimensional Health Locus of Control (MHLC) Scales. Health Educ Monogr 6: $160-170$.

40. Lip GY, Luscombe C, McCarry M, Malik I, Beevers G (1996) Ethnic differences in public health awareness, health perceptions and physical exercise: implications for heart disease prevention. Ethn Health 1: 47-53.

41. Downer SM, Cody MM, McCluskey P, Wilson PD, Arnott SJ, et al. (1994) Pursuit and practice of complementary therapies by cancer patients receiving conventional treatment. BMJ 309: 86-89.

42. Jobst KA (2009) The truth, the whole truth and nothing but the truth? A call for scientific rigor. J Altern Complement Med 15: 1147-1148.

43. Rees L, Weil A (2001) Integrated medicine. BMJ 322: 119-120. 